\title{
Acute Fulminant Colitis Caused by Idiopathic Mesenteric Inflammatory Veno-Occlusive Disease
}

\author{
James B. Canavan ${ }^{a} \quad$ Alan Coss $^{a} \quad$ Mary Leader $^{b}$ \\ Stephen E. Patchett ${ }^{\mathrm{a}}$ \\ Departments of a Gastroenterology and bPathology, Beaumont Hospital and the \\ Royal College of Surgeons in Ireland, Dublin, Republic of Ireland
}

\section{Key Words}

Mesenteric inflammatory veno-occlusive disease $\cdot$ Ischemic colitis - Mesenteric vascular occlusion · Necrosis · Colectomy

\begin{abstract}
Mesenteric inflammatory veno-occlusive disease (MIVOD) is an uncommon but important cause of bowel inflammation. MIVOD is characterised by lymphocytic inflammation and non-thrombotic occlusion of the mesenteric venules and veins. We present the case of a young man who presented with acute fulminant colitis, requiring colectomy. The differential diagnosis, pathogenesis and treatment are discussed. This case illustrates the rapid progression from 'well' to 'colectomy' that can occur with MIVOD. MIVOD should be considered in the differential diagnosis of colitis that does not respond to conventional medical treatment.
\end{abstract}

\section{Introduction}

Mesenteric inflammatory veno-occlusive disease (MIVOD) is an uncommon cause of intestinal ischaemia, characterised by mesenteric venulitis and non-thrombotic occlusion of mesenteric veins, in the absence of histological evidence of mesenteric arteritis or extra-intestinal vasculitis [1]. MIVOD causes colitis and uniformly requires treatment by surgical colectomy. Diagnosis is made by histological examination of the resected colon. We present the case of a young man presenting with a relatively short history of bloody diarrhoea, consistent with community-acquired gastroenteritis, but progressing over a short period to fulminant colitis, requiring colectomy. This case illustrates the rapid progression from 'well' to 'colectomy' that can occur with MIVOD. MIVOD should be considered in the differential diagnosis of colitis that does not respond to conventional medical treatment. 


\section{Case}

A thirty-two year-old man presented with a five-day history of bloody diarrhoea and crampy left iliac fossa pain. He was passing 10 bloody, liquid bowel motions per day, including nocturnal diarrhoea. He was taking no medicines. There was no past medical history. In particular, there was no history of gastrointestinal complaints, risks for infectious diarrhoea, asthma or vasculitis. Family history was unremarkable. He was apyrexial and normotensive. Abdominal examination was notable for a soft abdomen with left iliac fossa tenderness, without guarding or rigidity. Bowel sounds were normal. There were no extra-intestinal signs of inflammatory bowel disease, oro-genital ulceration or evidence of vasculitis. White cell count (WCC) was $13.8 \times 10^{9} / \mathrm{l}$, erythrocyte sedimentation rate (ESR) was $4 \mathrm{~mm} / \mathrm{h}$ and C-reactive protein (CRP) was $1.5 \mathrm{mg} / \mathrm{dl}$. Plain film of the abdomen was unremarkable. The initial clinical impression was one of acute infectious gastroenteritis. He was managed conservatively and was commenced on parenteral fluids.

By day 4 of his admission, he still was passing 6 bloody bowel motions per day and had not settled as expected. A flexible sigmoidoscopy was performed. This revealed inflamed and ulcerated mucosa in the descending colon, with rectal sparing. Histological examination showed ulcerated mucosa with fibrinoid necrosis. Hydrocortisone $100 \mathrm{mg}$ q.i.d. i.v. was commenced. Despite intravenous steroid therapy, the patient's stool frequency remained unchanged. On day 7 of his admission, he developed generalised abdominal pain with rigidity and guarding. His WCC rose to $27.0 \times 10^{9} / 1$, with an absolute neutrophil count of $23.8 \times 10^{9} / \mathrm{l}$. ESR was $21 \mathrm{~mm} / \mathrm{h}$ and CRP was $6.0 \mathrm{~g} / \mathrm{dl}$. A contrast-enhanced CT scan was performed, demonstrating pancolitis (舀. 1 ).

A decision was made to proceed to surgery. At laparotomy, the colon was found to be diseased with two markedly abnormal skip lesions in the transverse and descending colons. A subtotal colectomy was performed. Macroscopic examination of the resected colon showed two discrete areas of mucosal ulceration, oedema and necrosis, measuring 20 and $8 \mathrm{~cm}$ respectively. Microscopic examination demonstrated full-thickness inflammation, with marked oedema, particularly of the submucosa (fig. 2). The mucosa was necrotic and focally ulcerated. The muscularis propria also showed focal necrosis. No granulomata, fissuring or viral inclusions were seen. The arteries and arterioles were normal. However, a peri-venular lymphocytic infiltrate was seen, in areas distant from the necrosis (ig. 3 ). Histology confirmed a diagnosis of MIVOD.

The patient had an uncomplicated post-operative course. Convalescent serological investigations, including prothrombin time, activated partial thromboplastin time, fibrinogen, antithrombin, factor $\mathrm{V}$ Leiden, prothrombin G20210A mutation, proteins C and S, homocysteine, lupus anticoagulant, anticardiolipin antibodies and ANCA, were normal. CD59 expression was normal. Anti-nuclear factor was weakly positive (1:40). A magnetic resonance angiogram demonstrated a normal coeliac axis and superior mesenteric artery. Subsequent ileoscopy and rectal stump endoscopy were unremarkable. At 2 years follow-up, the patient is well and awaiting reversal of his ileostomy.

\section{Discussion}

MIVOD was coined by Flaherty et al. [1] to describe vasculitis and non-thrombotic occlusive disease of the mesenteric veins and venules, in the absence of evidence of extraintestinal vasculitis or other bowel disease. Patients present with abdominal pain, mucus per rectum, or bloody diarrhoea, of variable duration. Patients are usually under 50 years old and healthy prior to presentation.

The aetiology of MIVOD is incompletely understood. Cytomegalovirus infection [2] and certain drugs [3] have been implicated as aetiological agents in case reports. Implicated drugs include Rutoside (hydroxyethylrutoside), Reserpine, Methyldopa and Amiloride.

Inflammatory bowel disease is the major differential diagnosis. Inherited and acquired thrombophilia, including paroxysmal nocturnal haemoglobinuria, should be excluded. Behçet's disease [4] and Churg-Strauss syndrome [5] have been described to cause nonocclusive mesenteric venulitis. Mesenteric angiography was performed in one case series. 


\begin{tabular}{c|l|l|l}
$\begin{array}{c}\text { Case Reports in } \\
\text { Gastroenterology }\end{array}$ & $\begin{array}{l}\text { Case Rep Gastroenterol 2007;1:152-156 } \\
\text { D0I: 10.1159/000112222 }\end{array}$ & Published online: December 13, 2007 & $\begin{array}{l}\text { O 2007 S. Karger AG, Basel } \\
\text { ISSN 1662-0631 } \\
\text { www.karger.com/crg }\end{array}$ \\
\hline
\end{tabular}

This demonstrated ectatic, enlarged feeding arterioles with absent draining veins from the involved colonic and rectal segments [6].

Histological findings relate to disease distribution and severity. The histological appearance described above is characteristic of MIVOD. Other histological findings can include focal fibrinoid necrosis, thrombi of varying ages, neutrophilic venulitis and myointimal hyperplasia. Careful review should reveal no evidence of arteritis, granulomata or crypt abscess. Skip lesions may also occur, leading to confusion with Crohn's disease. Strictures have been described, indicating chronicity.

MIVOD characteristically fails to respond to appropriate treatment for inflammatory bowel disease. As MIVOD is a pathological diagnosis, surgery is both the definitive diagnostic and therapeutic procedure, following which patients are reported to thrive. Only one case of postoperative recurrence has been described, in a patient who previously had an incomplete colonic resection [7].

In summary, MIVOD is an uncommon entity that can cause an acute fulminant colitis, requiring surgical management. It should be considered in the differential diagnosis of fulminant colitis or bowel inflammation with clinical and pathological features that suggest, but are not entirely consistent with, inflammatory bowel disease. It should also be considered where colitis does not respond to conventional medical treatment.

Fig. 1. Axial contrast-enhanced CT image taken at the level of the body of L1 vertebra, demonstrating colitis. The transverse colon (arrows) is grossly abnormal and thickened due to mural oedema.

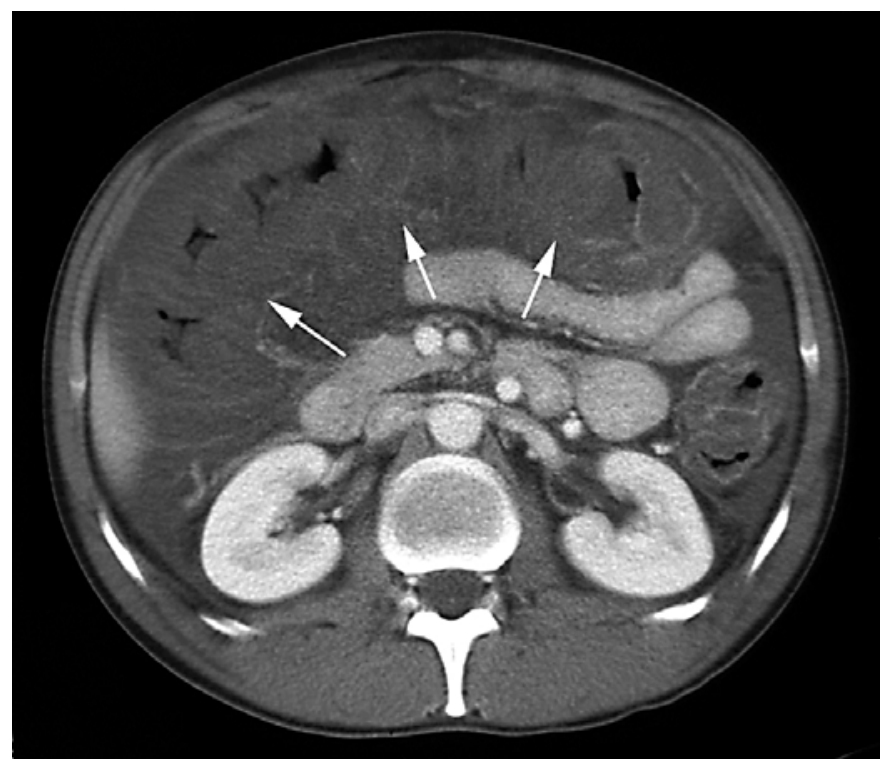




\begin{tabular}{c|l|l|l}
$\begin{array}{c}\text { Case Reports in } \\
\text { Gastroenterology }\end{array}$ & $\begin{array}{l}\text { Case Rep Gastroenterol 2007;1:152-156 } \\
\text { D0I: 10.1159/000112222 }\end{array}$ & Published online: December 13, 2007 & $\begin{array}{l}\text { @ 2007 S. Karger AG, Basel } \\
\text { ISSN 1662-0631 } \\
\text { www.karger.com/crg }\end{array}$ \\
\hline
\end{tabular}

Fig. 2. Histological image taken from the resected colon $(\mathrm{HE} \times 100)$, demonstrating focally ulcerated colonic mucosa (arrow A). The submucosa shows marked oedema and a light lymphocytic infiltrate (arrow B).

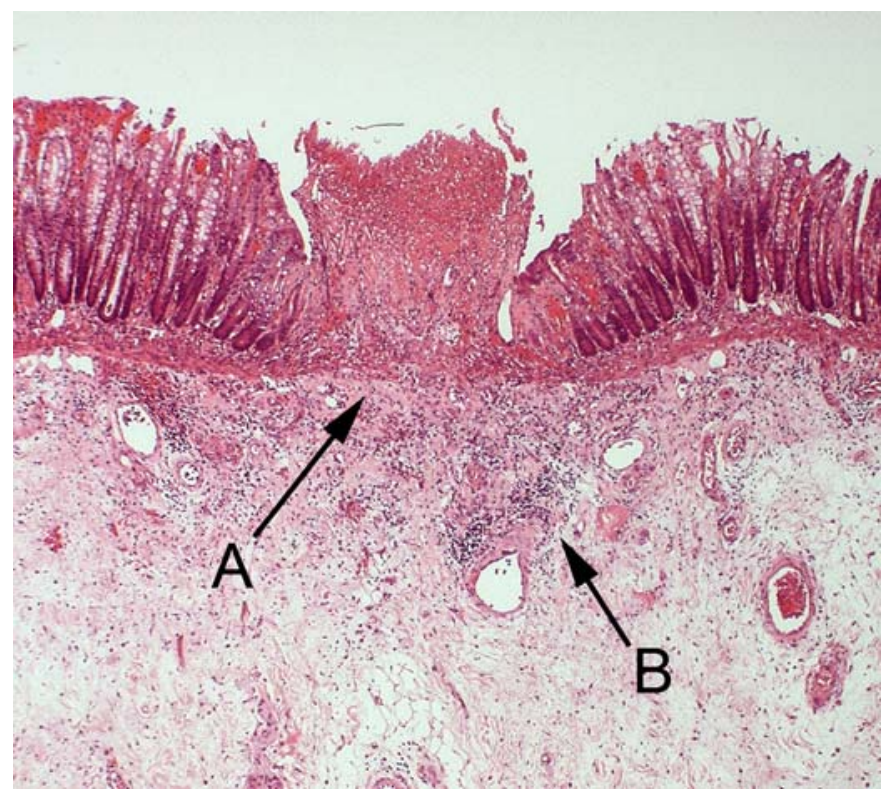

Fig. 3. This image $(\mathrm{HE} \times 400)$ shows submucosa and a dilated vessel with a peri-venular lymphocytic infiltrate (arrow), a histological feature of MIVOD.

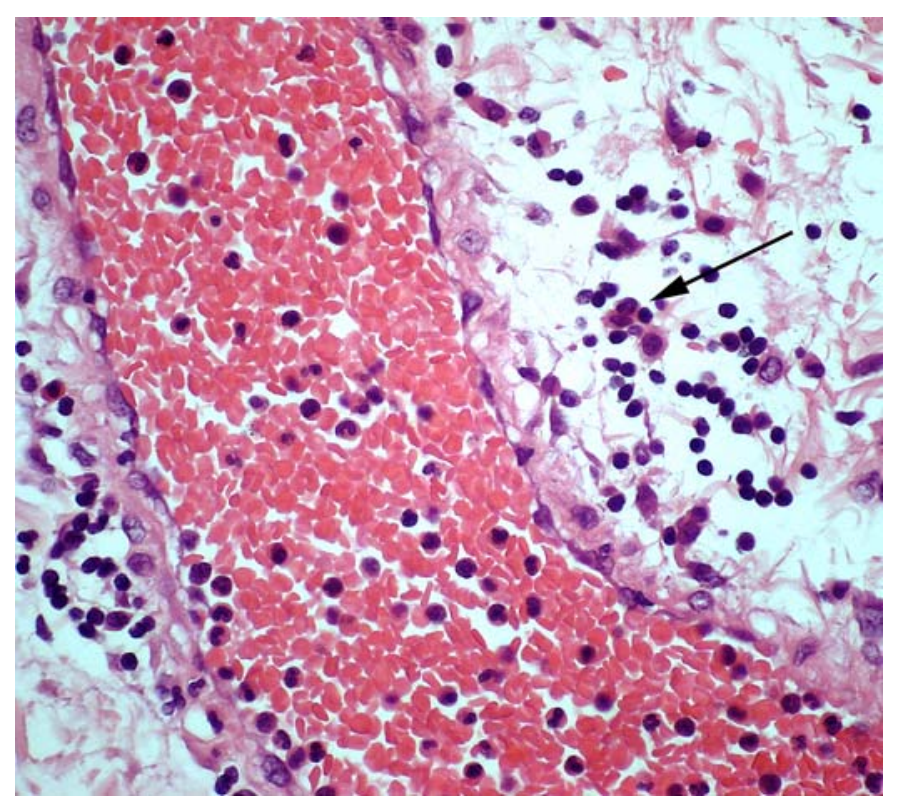




\section{References}

1 Flaherty MJ, Lie JT, Haggitt RC: Mesenteric inflammatory veno-occlusive disease. A seldom recognized cause of intestinal ischemia. Am J Surg Pathol 1994;18:779784 .

-2 Ailani RK, Simms R, Caracioni AA, West BC: Extensive mesenteric inflammatory veno-occlusive disease of unknown etiology after primary cytomegalovirus infection: first case. Am J Gastroenterol 1997;92:1216-1218.

3 Saraga EP, Costa J: Idiopathic entero-colic lymphocytic phlebitis. Am J Surg Pathol 1989;13:303-308.

4 Lee RG: The colitis of Behçet's syndrome. Am J Surg Pathol 1986;10:888-893.

5 Modigliani R, Muschart JM, Galian A, Clauvel JP, Piel-Desruisseaux JL: Allergic granulomatous vasculitis (Churg-Strauss syndrome). Report of a case with widespread digestive involvement. Dig Dis Sci 1981;26:264-270.

-6 Lavu K, Minocha A: Mesenteric inflammatory veno-occlusive disorder: a rare entity mimicking inflammatory bowel disorder. Gastroenterology 2003;125:236239.

7 Tempia-Caliera AA, Renzulli P, Z’graggen K, Lehmann T, Ruchti C, Buchler MW: Mesenteric inflammatory veno-occlusive disease: a rare cause of intestinal ischemia. The first description of recurrent disease. Digestion 2002;66:262-264. 